\title{
Shear wave velocities in the upper mantle of the Western Alps: new constraints using array analysis of seismic surface waves
}

\author{
Chao Lyu, ${ }^{1,2,3}$ Helle A. Pedersen, ${ }^{2,3}$ Anne Paul, ${ }^{2,3}$ Liang Zhao, ${ }^{1}$ Stefano Solarino ${ }^{4}$ \\ and CIFALPS Working Group* \\ ${ }^{1}$ State Key Laboratory of Lithospheric Evolution, Institute of Geology and Geophysics, Chinese Academy of Sciences, 100029 Beijing, China. \\ E-mail: zhaoliang@mail.iggcas.ac.cn \\ ${ }^{2}$ Université Grenoble Alpes, ISTerre, F-38041 Grenoble, France \\ ${ }^{3}$ CNRS, ISTerre, F-38041 Grenoble, France \\ ${ }^{4}$ Istituto Nazionale di Geofisica e Vulcanologia, CNT, I-16145 Genoa, Italy
}

Accepted 2017 April 24. Received 2017 April 19; in original form 2016 December 29

\begin{abstract}
SUMMAR Y
It remains challenging to obtain absolute shear wave velocities of heterogeneities of small lateral extension in the uppermost mantle. This study presents a cross-section of $V s$ across the strongly heterogeneous 3-D structure of the western European Alps, based on array analysis of data from 92 broad-band seismic stations from the CIFALPS experiment and from permanent networks in France and Italy. Half of the stations were located along a dense sublinear array. Using a combination of these stations and off-profile stations, fundamental-mode Rayleigh wave dispersion curves were calculated using a combined frequency-time beamforming approach. We calculated dispersion curves for seven arrays of approximately $100 \mathrm{~km}$ aperture and 14 arrays of approximately $50 \mathrm{~km}$ aperture, the latter with the aim of obtaining a 2-D vertical cross-section of $V s$ beneath the western Alps. The dispersion curves were inverted for $V s(z)$, with crustal interfaces imposed from a previous receiver function study. The array approach proved feasible, as $V s(z)$ from independent arrays vary smoothly across the profile length. Results from the seven large arrays show that the shear velocity of the upper mantle beneath the European plate is overall low compared to AK135 with the lowest velocities in the internal part of the western Alps, and higher velocities east of the Alps beneath the Po plain. The 2-D $V s$ model is coherent with (i) a $\sim 100 \mathrm{~km}$ thick eastward-dipping European lithosphere west of the Alps, (ii) very high velocities beneath the Po plain, coherent with the presence of the Alpine (European) slab and (iii) a narrow low-velocity anomaly beneath the core of the western Alps (from the Briançonnais to the Dora Maira massif), and approximately colocated with a similar anomaly observed in a recent teleseismic $P$-wave tomography. This intriguing anomaly is also supported by traveltime variations of subvertically propagating body waves from two teleseismic events that are approximately located on the profile great circle.
\end{abstract}

Key words: Europe; Surface waves and free oscillations; Continental margins: convergent.

\section{INTRODUCTION}

The driving forces of tectonic deformation and associated surface processes and hazards in mountainous regions (topography building and subsequent erosion, landslides, earthquakes, etc.) are seated in the mantle, and possibly in small-scale convection of the upper mantle (e.g. Faccenna et al. 2014). A better understanding of processes

\footnotetext{
* CIFALPS Working Group: Coralie Aubert, Marco G. Malusà, Qingchen Wang, Stéphane Guillot, Silvia Pondrelli, Simone Salimbeni, Stéphane Schwartz, Thierry Dumont, Tianyu Zheng and Rixiang Zhu.
}

at play requires geodynamic modelling based on high-quality images on the structure and dynamics of the upper mantle. However, seismic tomography is particularly challenging in mountainous areas due to strong lateral heterogeneities and therefore the need of particularly dense seismic networks. A challenge remains recovering high-resolution images of $V s$, a key indicator of temperature and compositional heterogeneity, across 3-D, narrow and strongly heterogeneous structures such as the western Alps.

The European Alps are part of the complex boundary zone between the European and African plates. They are the result of the Cretaceous to Palaeogene subduction of the Tethyan ocean and the European continental margin beneath the Adriatic microcontinent, 
and the subsequent continental collision between the European and Adriatic palaeomargins (e.g. Dewey et al. 1989; Handy et al. 2010 and references therein). The complex tectonic setting of the western Alps and their transition to the Apennines (arcuate shape, lateral change in subduction polarity with Adria being the upper plate in the Alps and the lower plate in the Apennines) results from a complex history including complex geometry of the palaeotrench, lateral changes in the polarity of the subduction, rollback of the Apenninic slab leading to the opening of the Ligurian Sea and counterclockwise rotation of Adria (e.g. Jolivet \& Faccenna 2000; Malusà et al. 2015). A specific point of interest is that the subduction complex of the western Alps, also including the eclogitized continental crust of the internal crystalline massifs, displays well-preserved outcrops of (U)HP rocks attesting deep burial and exhumation of continental crust down to mantle depth (Chopin 1984; Guillot et al. 2009; Zhao et al. 2015). Another point of interest is the potential role of the mantle in controlling the fast uplift of the external crystalline massifs, which include the highest summits of the Alps (e.g. the Mont Blanc), in the last 2 My (Fox et al. 2015). This uplift has been partly explained by the break-off of the Tethyan-European slab (Nocquet et al. 2016) inferred from the seismic tomography of Lippitsch et al. (2003). However, a recent seismic tomography of the same region (Zhao et al. 2016a) suggests that the European slab is not broken off, and that a low-velocity anomaly exists in the lower lithosphere and asthenosphere beneath the core of the Western Alps. A high-resolution shear wave imaging of the mantle structure of the Western Alps may provide key information complementing the body wave model of Zhao et al. (2016a) to further understand the impact of mantle structure on surface processes and topographic evolution.

Regional surface wave tomographies based on two-station measurements and full-waveform inversion (e.g. Weidle \& Maupin 2008; Legendre et al. 2012; Fichtner et al. 2013; Zhu et al. 2015; Meier et al. 2016) have successfully provided large-scale images of the upper mantle beneath Europe. Array processing techniques using large arrays (a few hundred kilometres aperture) have already been used by many groups to obtain very well-constrained uppermantle structure (e.g. Friederich 1998; Pollitz 1999; Bruneton et al. 2004; De Barros et al. 2008; Tang \& Chen 2008; Alvizuri \& Tanimoto 2011; Maupin 2011; Salaün et al. 2012; Pedersen et al. 2013; Ikeda \& Tsuji 2014) and ambient noise tomography techniques are now standard for investigating crustal structure for the Alpine region (see Stehly et al. 2009; Molinari et al. 2015). While the usage of arrays is becoming standard for estimating great-circle deviations (e.g. Alsina \& Snieder 1996; Maupin 2011; Foster et al. 2014a; Pedersen et al. 2015), and has been used to improve two-station measurements (Baumont et al. 2002; Bourova et al. 2005; Kaviani et al. 2007; Tanimoto \& Prindle 2007; Foster et al. 2014b), the usage of small arrays is rather sparse for investigating the lithosphere (e.g. Cotte et al. 2002; Pedersen et al. 2003). We here explore the complementary imaging opportunities given by array analysis of surface waves across the western Alps, using arrays with an aperture smaller than the wavelengths under study. A fundamental assumption behind this approach is that the observed phase velocities approximately correspond to the phase velocity of a tabular medium ('structural velocity'; Wielandt 1993) with interfaces at the same depth as those locally beneath the array within a laterally varying medium. This is a necessary condition to invert the observed phase velocities into a meaningful model. Through waveform modelling including multiple scattering, Bodin \& Maupin (2008) explored differences between observed (array analysis) and structural velocities of fundamental-mode Rayleigh waves within a 3-D structure (with a low-velocity anomaly at 40-100 km depth). They demonstrated that also in a 3-D structure, and if events from different azimuths are used in the data analysis, the observed phase velocities are correctly located in the horizontal direction, and that the phase velocity change above the low-velocity anomaly may be somewhat damped, depending on wavelength, array size and anomaly size.

We are here taking the next natural step in the array analysis: using it to provide a shear velocity cross-section of the Alps, using small adjoining arrays. As the measurements are sensitive to noise, care should be taken to not overinterpret individual array measurements. On the other hand, such measurements give valuable unique constraints of absolute shear velocities with a lateral resolution that is presently not possible to obtain from any other techniques. The CIFALPS (China-Italy-France Alps seismic) array (Zhao et al. 2016b) was therefore designed as a test case for this approach, with a central, densely instrumented, profile well adapted for body wave tomography, receiver function analysis, etc., with additional sparse stations installed approximately $40 \mathrm{~km}$ from the central line. We additionally benefited from data from permanent stations on both sides of the CIFALPS line.

\section{DATA AND METHODS}

\subsection{Data and pre-processing}

The CIFALPS (Zhao et al. 2016b) was a temporary broad-band seismic network that operated for 14 months between 2012 July and 2013 September. In this study, we used vertical component data from 55 CIFALPS temporary broad-band stations, with the addition of 37 neighbouring permanent stations from the RESIF network in France (network code FR; RESIF 1995) and Italy (network codes GU, University of Genova 1967; and IV, INGV Seismological Data Centre 1997) for which continuous data streams were available (see station configuration in Fig. 1). Approximately half (46) of the stations were located along a $320 \mathrm{~km}$ long WSW-ENE transect with an interstation distance of approximately $5 \mathrm{~km}$ in the central part of the Alps, and $10 \mathrm{~km}$ in the external parts. Off-profile (45) stations were part of the array geometry with the aim of making it possible to perform array analysis. We later refer to the linear profile $\mathrm{A}-\mathrm{A}^{\prime}$ that follows the CIFALPS transect, also shown in Fig. 1.

The initial data set was composed of all worldwide events of magnitude 6 and more that were recorded during the CIFALPS experiment, with the addition of regional events (epicentral distance $<20^{\circ}$ ) of magnitude 5.5 and more. Prior to further processing, we applied for each event data standard processing: removing mean and trend, applying zero-phase bandpass filter $(0.005-0.1 \mathrm{~Hz})$, decimation and deconvolution from instrument response. Traces with easily identifiable instrumental problems such as spikes, poor signal-tonoise ratio and faulty components were automatically removed. Fig. $\mathrm{S} 1$ in the Supporting Information shows an example of a seismic section of filtered data.

All pre-processed data were subsequently filtered with phasematch filter (Levshin et al. 1989) to extract the fundamental-mode Rayleigh waves by a semi-automatic approach. We first calculated and visually inspected the output of multiple filter analysis of data from OGAG, a permanent station located near the centre of the profile. The group velocity dispersion curve and the width of the applied time window (at least $300 \mathrm{~s}$ ) were chosen interactively and the output of the filter was also visually inspected. We only kept events for which the Rayleigh wave fundamental mode was clearly identifiable and separated from other arrivals, such as, for example 


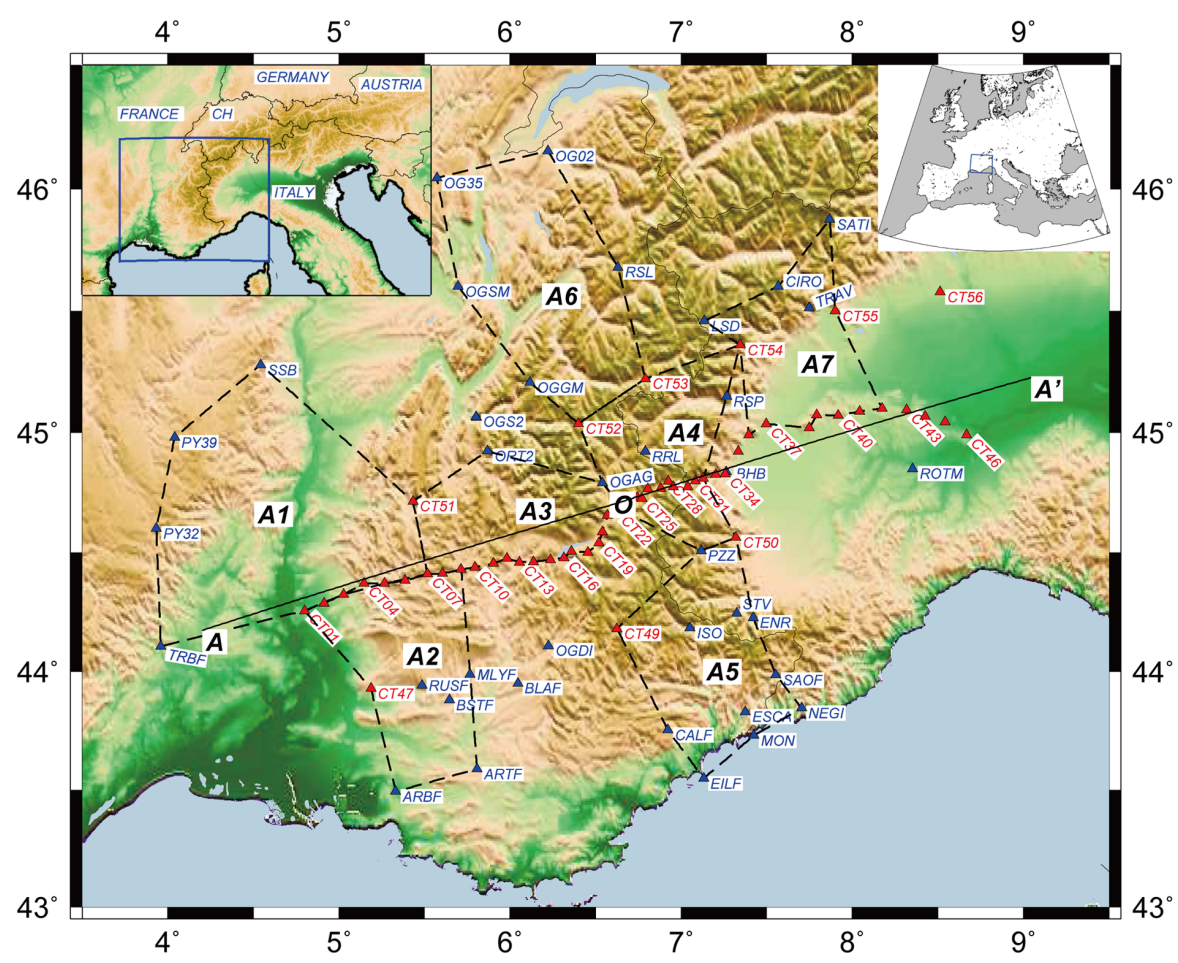

Figure 1. Map of seismic stations and large arrays. CIFALPS and permanent stations are shown as red and blue triangles, respectively. Groups of stations connected by black dashed lines are the large arrays, numbered A1-A7. The continuous black line shows profile AA'. The origin of distance measurements along $\mathrm{AA}^{\prime}(x=0 \mathrm{~km})$ is shown by $\mathrm{O}$. $\mathrm{CH}$ : Switzerland.

higher modes. For each accepted event, we then applied the filter to all stations, correcting for the difference in epicentral distance. The small interstation distances as compared to the epicentral distance justify this procedure, as the group velocity dispersion curve at different stations within the array is practically the same. In the events of lack of data or poor signal-to-noise ratio at OGAG, we used a neighbouring temporary station with high signal-to-noise ratio. For all events, we plotted seismic sections of all the filtered data in different period intervals to identify and if necessary manually discard data from stations with poor data quality. The final event data set (see event configuration in Fig. 2) after quality selection comprises five events with magnitude $\geq 5.5$ and epicentral distance $<20^{\circ}$ and 93 events with magnitude $\geq 6$ and epicentral distance between $20^{\circ}$ and $110^{\circ}$.

\subsection{Array analysis}

The data analysis was aimed at obtaining phase velocity dispersion curves, and subsequently estimates of 1-D $V s(z)$ profiles, beneath a set of arrays. Most array processing methods for teleseismic events are based on the hypothesis of plane incoming waves, and further assuming that averaging over a set of events with a good backazimuth distribution will suppress possible influence of diffraction outside the array. As shown in Fig. 2, the azimuth distribution of the events we used was good, despite some dominance of events in the northeast quadrangle. In an area of laterally homogeneous crust and upper-mantle structures, and in absence of scattering outside the array, increasing the array size reduces the measurement error. In a very heterogeneous area, such as the Alps, this effect is counterbalanced by an increase in coherent noise due to non-plane waves and local scattering. We therefore present results from two different array sizes: relatively large arrays (all shown in Fig. 1,

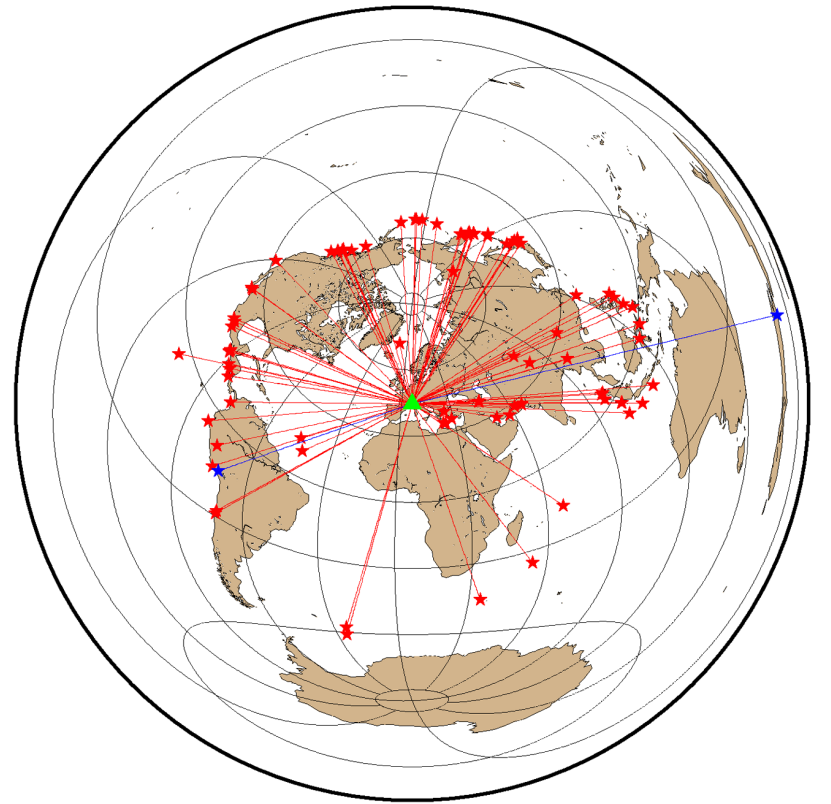

Figure 2. Earthquake map (Lambert azimuthal equal-area projection). We used 98 seismic events (red stars) to calculate phase velocity dispersion curves. The green triangle indicates the centre of the CIFALPS array. Great circles between events and the centre of the array are shown with red lines. The blue stars refer to events for which traveltime delays of body waves are shown in Fig. 5(e).

arrays A1-A7) that will indicate average dispersion over an area of approximately $100 \mathrm{~km} \times 100 \mathrm{~km}$, and a set of smaller arrays, a1-a14 of approximately $50 \mathrm{~km} \times 50 \mathrm{~km}$ located on the north and south sides of the CIFALPS transect (all shown in Fig. 5a, arrays 
(a) 4

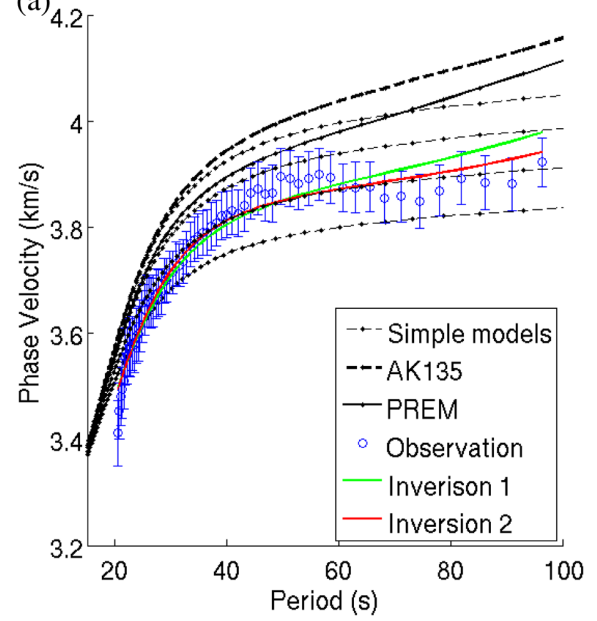

(b)

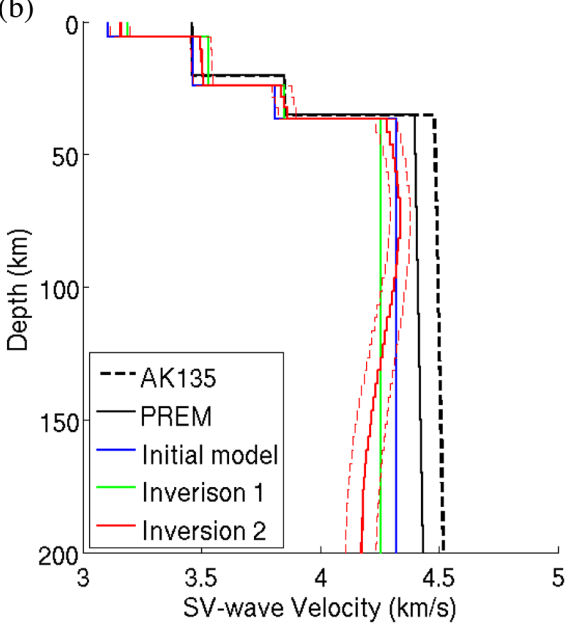

Figure 3. Example of inversion strategy (array A2). (a) Dispersion curves (fundamental-mode Rayleigh waves). Blue: observed phase velocity and associated error bars. Green: theoretical dispersion curve for the model obtained in Inversion 1 (200 km thick constant-velocity layer in the upper mantle). Red: theoretical dispersion curve for the final model obtained in Inversion 2, corresponding to our final model. Thick dashed black line: dispersion curve for AK135. Thick solid black line: dispersion curve for PREM (Dziewonski \& Anderson 1981) modified by replacing crust model with that of AK135. Thin black dashed lines: theoretical dispersion curves for models with identical crustal structure and different upper-mantle velocities (constant 4.48, 4.4, 4.3 and 4.2 km s ${ }^{-1}$ ) across $200 \mathrm{~km}$ thickness in the uppermost mantle. (b) Earth models $V s(z)$ : dashed black line: AK135. Solid black line: PREM. Blue line: starting model for Inversion 1. Solid green line: end model of Inversion 1. Solid red line: final model, which is the output model of Inversion 2. Dashed red lines: uncertainties of the resulting 1-D shear wave velocity of Inversion 2.

a1-a14). The latter cover an area sufficiently small to make a crosssection along the CIFALPS transect, and each takes into account the crustal structure obtained by receiver functions (Zhao et al. 2015), as the lateral resolution of the two methods becomes comparable (and comparable to the width of the crustal blocks with laterally homogeneous structure).

The main steps of the array method are discussed briefly here; we refer to Pedersen et al. (2003) and supporting information of Pedersen et al. (2013) for further detail. It is essentially a mixed timefrequency domain beamforming with an output relatively similar to that obtained by beamforming using, for example $f-k$ analysis (for a comparison, see Pedersen et al. (2015), but with a slightly better outlier control, and a frequency-dependent smoothing of the phase).

The Rayleigh surface wave phase velocity of one array was measured in three main steps.

(1) For each event $k$, the time delay $\Delta t_{i j k}(f)$ between each pair $(i, j)$ of stations in the array was measured as a function of frequency $f$ using Wiener filtering. We use Wiener filtering to smooth the spectrum of the cross-correlation of the two signals by multiplying the cross-correlation with a Hanning window (centred on the time of maximum in the cross-correlation). One problem of this method is that the Hanning window must contain several oscillations of the longest period. On the other hand, applying shorttime windows will decrease the influence of noise. Considering the wide period interval used (15-100 s), different orders of the Hanning window were therefore adapted to different period intervals. We used three overlapping windows (periods 10-50, 40-80 and 70-100 s) and calculated the phase of the smoothed spectrum in each window. In overlapping parts, we used a linear-weighted average so that at each endpoint of the overlapping section, we ensured continuity with the neighbouring points. By this procedure, we obtained the smooth phase difference $\phi_{i j k}(f)$ and consequentlythe time delay $\Delta t_{i j k}(f)$ was calculated as $\phi_{i j k}(f) / 2 \pi f$. Note that due to the short interstation distance, there is no $2 \pi$ uncertainty: incorrect phase unwrapping gives unrealistic, and therefore detectable, apparent interstation velocities.

(2) Assuming a plane wave propagating across the array, for each event and at each frequency, we estimated the phase velocity $C_{k}(f)$ and backazimuth $\theta_{k}(f)$ by using the L1 norm to minimize the sum of the absolute time difference between predicted and observed time delays. It was then possible to calculate the interstation distance $D_{k}(f)$ projected onto the slowness vector. The output of this step was, for each event and frequency, observed time delays associated with estimated projected interstation distances. Furthermore, events and frequencies for which the estimated velocity was outside the interval $2-5 \mathrm{~km} \mathrm{~s}^{-1}$ or for which the data fit (L1 norm) was above 0.4 were rejected from further analysis.

(3) For each frequency, $\left(D_{k}(f), \Delta t_{i j k}(f)\right)$ couples over all the events should fit a straight line through the origin, with the slope being the slowness at frequency $f$. We therefore calculated the bestfitting slope, using the L1 norm. To further control outliers, we used only data points for which the coherence associated with the observed time delay was more than 0.9 . The associated uncertainty was calculated as explained in Pedersen et al. (2003), where we used the median fit to the line for the uncertainty estimation, based on the velocity change incurred if the median fit was subtracted from the time delays predicted at the furthest distance. By combining information from different frequencies, we constituted the phase velocity dispersion curve and associated uncertainties between 15 and 100 s period. An example, for array A2, is shown in Fig. 3.

A biproduct of the analysis step (2) is that $\theta_{k}(f)$ gives insight to the great-circle deviation, that is, the difference between the observed backazimuth $\theta_{k}(f)$ and the great circle between earthquake and the centre of the array in question. We generally confirm previous results by Pedersen et al. (2015), Fig. S2 in the Supporting Information which shows that the average deviation over all events is $8^{\circ}-10^{\circ}$ for periods less than $30 \mathrm{~s}$, and decrease to a constant level $\left(5^{\circ}\right)$ which may in part be created by data uncertainty, at periods over $50 \mathrm{~s}$. Individual array observations and events did show a large 
scatter, which may be partly due to local structure, and partly due to noise in data. We do indeed have some observations of systematic changes of great-circle deviations across the array. The average deviation and details on how this average was obtained is found in Fig. S2 in the Supporting Information, as well as three examples for individual earthquakes in Fig. S3 in the Supporting Information. A thorough discussion of great-circle deviations and their dependency on station and source locations is beyond the scope of this work; we refer to Foster et al. (2014a) and Pedersen et al. (2015) for in-depth studies on this subject.

\subsection{Inversion for shear velocity $V s(z)$}

To invert the Rayleigh wave dispersion curves for $S$-wave velocity as a function of depth, we used an iterative, weighted inversion (Herrmann 2013) which allows to define strong discontinuities as well as depth intervals with a smooth velocity model, through a smoothing parameter imposed by the user. The crustal model is constrained by receiver functions and gravity modelling along the CIFALPS transect (Zhao et al. 2015), and by receiver functions at a larger scale (Lombardi et al. 2008) so we imposed the layer thickness in the crust based on these studies while we imposed smooth velocity variations in the mantle. With good constraints on strong interfaces, we inverted for $V s$ only. Small remaining errors in interface depth would translate into slightly biased velocities immediately above and/or below them, and there is, even if interface depths are exact, a trade-off between lower crustal and uppermost mantle velocities. We therefore only interpreted our final models below $80 \mathrm{~km}$ depth. It was not possible to retrieve information on anisotropy, first because azimuthal variations of phase velocity could either be attributed to heterogeneities outside the array, and secondly because of data scatter.

Because the dispersion characterizes integration over a depth range of the velocity structure, the inversion problem is strongly non-unique and influenced by relatively subjective choices, whether the inversion method is linearized or non-linear. We deliberately aimed at obtaining the simplest possible $V s(z)$ model while obtaining a reasonable data fit. The inversion therefore took place in two steps.

In the first inversion, we used a starting model made of (from top to bottom): (1) the initial crustal model described above, (2) a $200 \mathrm{~km}$ thick constant-velocity layer beneath Moho and (3) a number of $50 \mathrm{~km}$ thick layers down to $700 \mathrm{~km}$ depth with initial velocities from AK135 (Kennett et al. 1995). While the inverted model was, at best, resolved to $200 \mathrm{~km}$ depth, we inverted to $700 \mathrm{~km}$ depth to avoid the propagation of errors from the deep parts of the model into the resolved part. In this first inversion, we used five theoretical dispersion curves with identical crustal structures and different velocities in the upper mantle to set the initial shear velocities in the top $200 \mathrm{~km}$ of the mantle. Using this simple model, the first inversion refined the average shear velocity in the upper mantle, which was subsequently used in the starting model for the second inversion.

In the second inversion, we refined the $200 \mathrm{~km}$ thick constant layer velocity of upper-mantle structure into $5 \mathrm{~km}$ thick layers, and applied smoothing to how the velocities can evolve with depth. The same approach was used for the crust but adapting the thickness of the layers so as to respect the depth of the major interfaces. The convergence rate was variable for different dispersion curves, but due to the strong smoothing of the mantle velocities the inversion was stable also over many iterations. We iterated the inversion four times to obtain the final $V s(z)$ model.
Fig. 3 illustrates the two steps. The observed dispersion curve (blue points with associated error bars in Fig. 3a) and constantvelocity uppermost mantle dispersion curves (thin dashed black lines in Fig. 3a) made it possible to define an initial model (blue continuous curve in Fig. 3b) for the first inversion, which after inversion gave the input model (green continuous curve in Fig. 3b) for the second inversion. The equivalent dispersion curve (green line in Fig. 3a) was, in this case as for all the other arrays, a good first approximation to the observed dispersion curves, despite some systematic differences. The second inversion yielded a smooth and simple mantle model (red continuous curve in Fig. 3a), with a good fit to the observed dispersion curve.

\section{RESULTS}

\subsection{Lateral variability of lithospheric structure from seven large aperture arrays}

The choice of the large aperture $(\sim 100 \mathrm{~km})$ arrays was constrained by the station configuration, but mainly determined by present knowledge of the lithospheric structure of the Western Alps. The criteria were that the array should if possible (1) be located above a relatively homogeneous crustal structure as inferred from the receiver function model of Zhao et al. (2015); and (2) not be located above a strong lateral heterogeneity as determined by the $P$-wave upper-mantle tomography by Zhao et al. (2016a) that integrates CIFALPS data. We finally identified seven useable arrays (A1-A7 in Fig. 1, with Table S1 in the Supporting Information showing the stations used for each large array).

For the inversion of dispersion curves from arrays A2, A3 and A7, we used the receiver function model computed by Zhao et al. (2015) along the CIFALPS transect. This model has a subhorizontal Moho beneath those arrays. For arrays A1, A5 and A6, we used the crustal model of Lombardi et al. (2008). A4, located in an area including the Ivrea Body, represents a challenge as the crust and uppermost mantle have very strong heterogeneities across the array, including a vertical stack of crust-mantle-crust layers (Zhao et al. 2015). For that array, we estimated an equivalent Moho depth of $47 \mathrm{~km}$, based on lateral averages of the Zhao et al. (2015) model.

Fig. 4 shows the seven dispersion curves and associated mantle models. These models are a first indication of large lateral variations in shear wave velocities in the study area. West of the Alps (A1, A2 and A3), the average velocities in the uppermost mantle down to $100 \mathrm{~km}$ depth are compatible with previously observed seismic shear velocities in Phanerozoic Europe of approximately $4.4 \mathrm{~km} \mathrm{~s}^{-1}$ as observed in regional studies (e.g. Weidle \& Maupin 2008; Legendre et al. 2012), excepted areas having undergone, for example recent basaltic volcanism (Meier et al. 2016). We additionally observe that velocities decrease at depth. The exact thickness of the lithosphere is difficult to estimate using fundamental-mode surface waves (e.g. Bartzsch et al. 2011). However, our smoothed $V s(z)$ profiles are west of the Alps, they are compatible with a lithospheric thickness of approximately $100 \mathrm{~km}$, as observed in other areas of Phanerozoic Europe or in regional studies using surface waves (e.g. Dost 1990; Cotte et al. 2002) and $S$-receiver functions (Geissler et al. 2010). Artemieva et al. (2006) also provide lithospheric thicknesses of approximately $100 \mathrm{~km}$ beneath most of Phanerozoic Europe, based on global models such as Shapiro and Ritzwoller (2002), and on integrated modelling.

We observe high velocities east of the study region (A7, Po Plain), a result in agreement with models of a subducting slab beneath the 
(a)

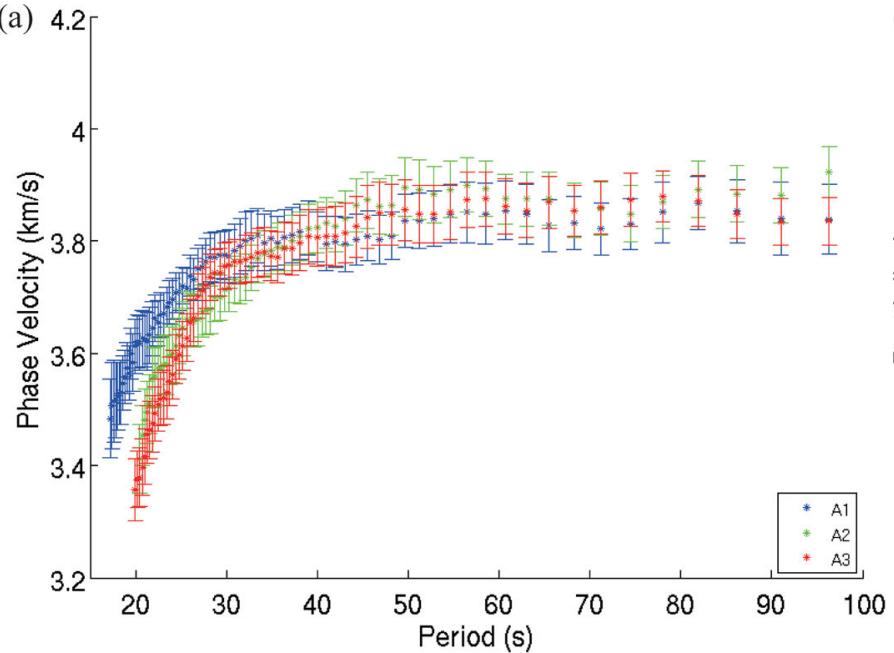

(b) 4.2\ulcorner

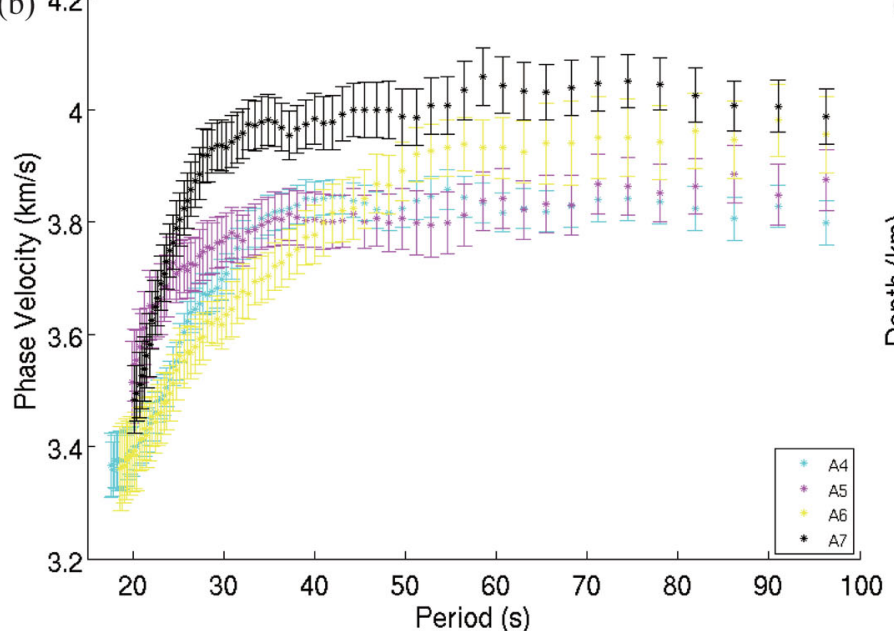

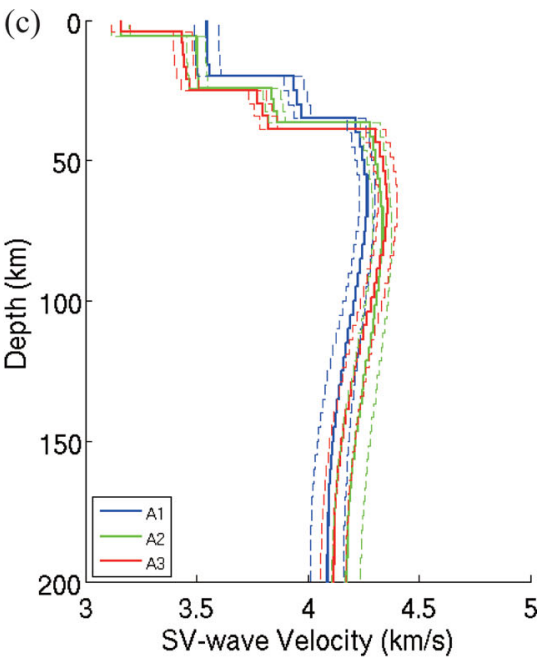

(d)

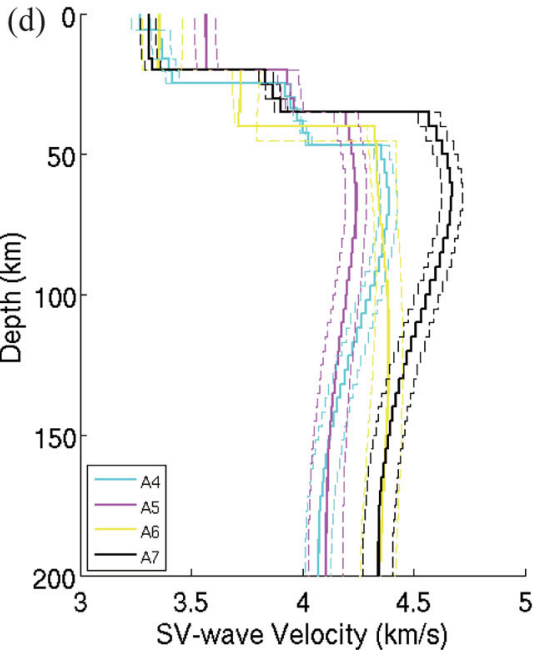

Figure 4. Dispersion curves (coloured dots) and shear velocity models $V s(z)$ of the seven large arrays A1-A7. (a) and (b) Dispersion curves (fundamental-mode Rayleigh waves). The colours refer to the array number, see also Fig. 1. (c) and (d) Shear velocity $V_{s}(z)$ as inferred from the dispersion curves in (a) and (b). Solid coloured lines: the final model output model of Inversion 2, using the same colour coding as in (a) and (b). Dashed coloured lines: uncertainties of the resulting 1-D shear wave velocity of Inversion 2 .

Po plain (Kissling 1993; Spakman et al. 1993; Lippitsch et al. 2003; Piromallo \& Morelli 2003). A4, A5 and A6, located in the central part of the western Alps, have associated $V s(z)$ that are very variable and complex (A5 and A6), exemplifying that the array size may not be adequate due to the small lateral scale of lithospheric heterogeneity in those areas. They do however give an indication of anomalously low-mantle velocities beneath both A4 and A5, a feature that we shall further explore in the following section.

\subsection{2-D $S$-wave velocity cross-section along the CIFALPS transect from 14 small arrays}

The primary objective of this section is to obtain a cross-section of shear wave velocities along the CIFALPS transect, based on phase velocity measurements in $\sim 50 \mathrm{~km}$ aperture arrays. Decreasing array size implies a trade-off as the measurement error increases due to random noise but decreases with regards to scattering and interfering waves (non-plane wave fronts). The trade-off will vary along the transect, depending on the array size and heterogeneity of the local structure. After numerous tests, we chose to define 14 arrays, by using stations from the CIFALPS transect and at least two off-transect stations. Arrays a1-a5 were located south of the CIFALPS transect, while arrays a6-a14 were located north of it. Fig. 5(a) shows the geometry of 14 arrays, and Table S1 in the Supporting Information lists the stations used for each array. As an additional quality check, we verified that the average dispersion curve over adequate selections of small arrays was compatible with the dispersion curve from the nearest and/or overlapping large array (see Fig. S4, Supporting Information).

An extra advantage of using the small arrays is that their lateral extension makes it relevant to use information from receiver functions along the CIFALPS transect (Zhao et al. 2015), as the scale of resolution for the two methods are approaching. We first attempted joint inversions of dispersion curves and receiver functions from nearby stations, but the individual receiver functions were of insufficient quality to allow for inversion beneath the central part of the Alps. In particular, the amplitude ratio between the converted $P$-to$S$ wave at Moho and the incident $P$ wave was in several locations too high to be modelled with simple 1-D models, thereby inducing unrealistic velocity jumps at Moho. Late arrivals in the receiver functions, which we attribute to 3-D effects, additionally resulted in spurious mantle discontinuities. Finally, in the western and eastern parts of the transect, the receiver functions were influenced by 

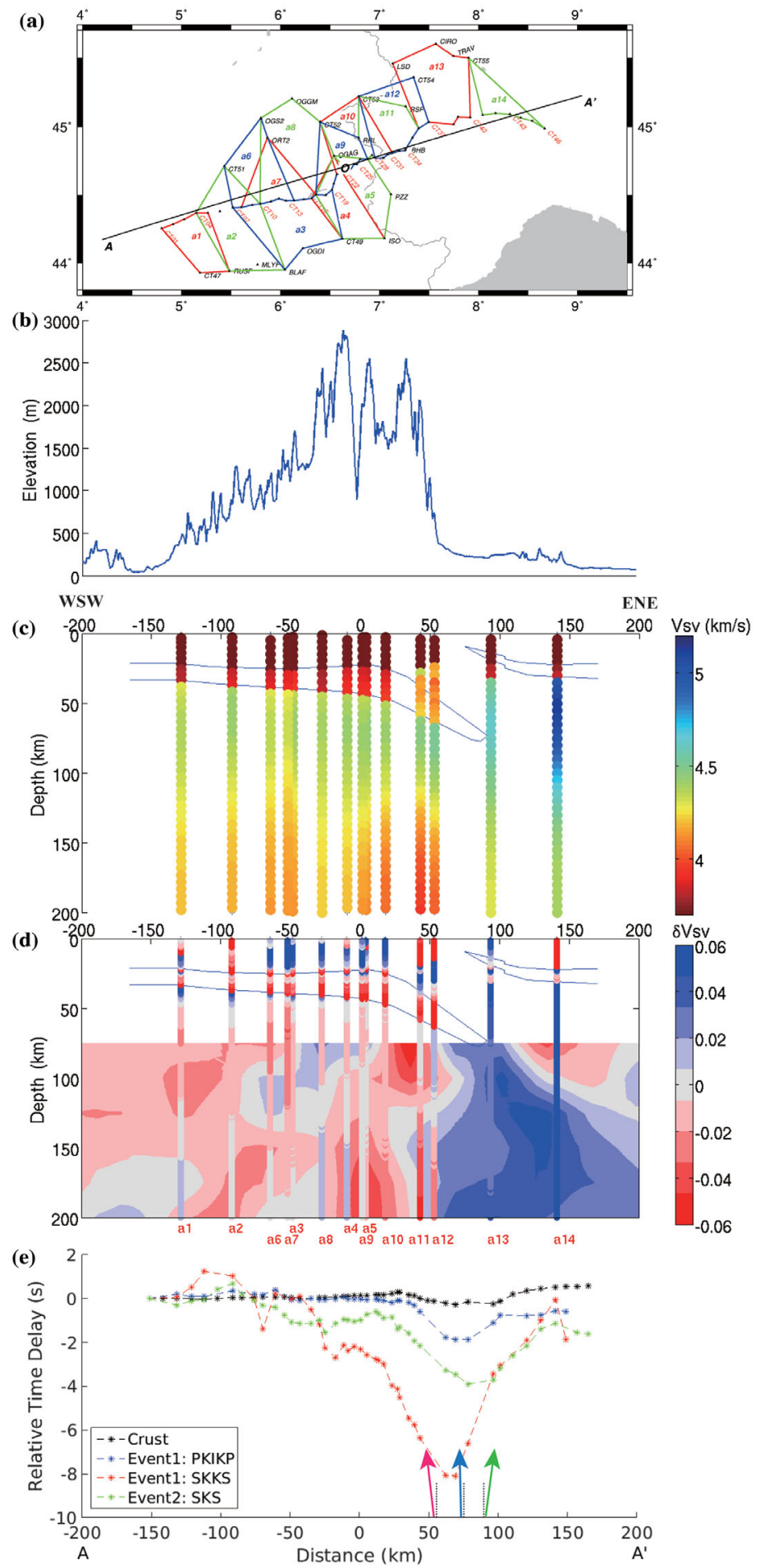

Figure 5. Vs model and relative body wave traveltimes. (a) Geometry of small arrays a1-a14. Station list for each array can be found in Table S1 in the Supporting Information. (b) Topography along the profile $\mathrm{AA}^{\prime}$. (c) Absolute $V s$ along the CIFALPS profile $\mathrm{AA}^{\prime}$ based on the results from 14 small arrays, each $V s$ profile projected onto the CIFALPS profile using the centre of mass of the array. (d) Relative $V s$. The perturbations are relative to the horizontal average calculated at each depth, that is, relative to the average $V s(z)$ profile (see Fig. S4 in the Supporting Information). This representation corresponds to what is obtained by teleseismic body wave tomography, with the aim of comparing to the model by Zhao et al. (2016a), which is shown as the coloured background, using an identical colour scale. (e) $P$ and $S$ relative time delays with respect to the westernmost stations for two events located approximately in the same azimuth as the CIFALPS reference profile (blue stars in Fig. 2). Event 1 was located at epicentral distance $170.5^{\circ}$ towards the ENE of the CIFALPS profile. Two phases were observed for Event 1: PKIKP (blue line) with an incidence angle to vertical of $1.3^{\circ}$ and SKKS (red line) with an incidence angle to vertical of $6.5^{\circ}$. Event 2 was located $92.6^{\circ}$ towards the WSW of the CIFALPS profile. The analysed phase, SKS (green line) has an incidence angle to vertical of $7.5^{\circ}$. The incidence to vertical is shown by the solid arrows. Relative time delays (with respect to the westernmost station) assuming vertical propagation within the crustal model of Zhao et al. (2015) and using a homogeneous mantle below, are shown as black stars. 
strong resonance effects beneath the thick basins of SE France and of the Po plain. We therefore used the final model by Zhao et al. (2015) to define the depth to crustal interfaces. Within each crustal layer, we let $V s$ in the crust free to vary during the inversions, as the $V_{S}$ in the crust was not constrained from receiver functions. Due to the conservative choices on model parametrization and inversion approach, the errors and their changes with depth on these models are very similar to the ones shown in Fig. 4.

Velocities in the lower crust and uppermost mantle should be interpreted with great caution due to the trade-off between crustal and upper-mantle velocities. It is nevertheless notable that in the western part of the profile (from -130 to $+20 \mathrm{~km}$ ), the $V_{S}$ is quite homogeneous and lower than $4.0 \mathrm{~km} \mathrm{~s}^{-1}$ suggesting that the lower crust beneath the western Alps is relatively felsic (e.g. Goffé et al. 2003) as observed beneath Tibet (Mechie et al. 2012). Eastward, beneath the internal Alps ( +50 in Fig. 5c), $V s$ increases up to $4.2 \mathrm{~km} \mathrm{~s}^{-1}$. It can be either interpreted as an increase of the mafic component or an increase of the velocity with the increase of the metamorphic grade. Considering that the tip of the European lower crust is of the same composition as the western part, the $V_{S}$ increase is compatible with the progressive eclogitization (Zhao et al. 2015) of a dominant felsic lower crust.

Fig. 5 shows the output of the inversions in the form of a crosssection, where the centre of mass of each array is projected onto the $\mathrm{A}-\mathrm{A}^{\prime}$ profile (see the geometry of small arrays a1-a14 in Fig. 5a and station list is in Table S1 in the Supporting Information). Fig. 5(b) shows the topography along the profile $\mathrm{AA}^{\prime}$. As absolute $V s$ yields insight to the physical properties of the medium, we show both a cross-section with absolute velocities (Fig. 5c), and a cross-section where, at each depth, we calculated variations in percent to the horizontal average (Fig. 5d). The average $V s(z)$ is shown in Fig. S4 in the Supporting Information. This average $V s(z)$ is virtually identical whether we calculate the average over arrays a1-a14 or over four large arrays that cover approximately the same area (see Fig. S4, Supporting Information), indicating that the dispersion curves from the small arrays are not systematically biased even at long periods where the array size is approximately a fifth to a tenth of the wavelength. The representation in Fig. 5(d) is equivalent to output from teleseismic body wave tomographies, which yield velocity variations with respect an unknown velocity model that is laterally homogeneous, but that varies with depth.

A first observation, as seen from Fig. 5(c), and as discussed in the beginning of this section, is the very good lateral continuity between the independent measurements of each array, which lends additional reliability to the data analysis and the associated quality control. In terms of structure, the main feature of Fig. 5(c) is the decrease in seismic velocities below $100 \mathrm{~km}$ depth in the western part of the cross-section, tentatively associated with the lithosphereasthenosphere boundary and in agreement with the observations from arrays $\mathrm{A} 1-\mathrm{A} 3$ (see also previous section). It is tempting to interpret the deepening of the top of the low-velocity layer that is approximately parallel to the European Moho as an eastward dipping lithosphere-asthenosphere boundary, in agreement with the interpretation of a previous body wave tomography of the area (Lippitsch et al. 2003), but this interpretation is supported by only two array measurements. Indeed, due to poor data quality for stations located in the Po plain, we only have two $V_{S}(z)$ profiles available east of the Alps. On the other hand, the very high velocities $\left(\sim 5 \mathrm{~km} \mathrm{~s}^{-1}\right)$ of the lithospheric mantle beneath the Po plain are well constrained in the inversions both in the two easternmost small arrays (a13 and a14), as well as in the larger array A7. A final observation is that very low velocities $\left(<4 \mathrm{~km} \mathrm{~s}^{-1}\right)$ are visible in the deepest part of the model $(z>120 \mathrm{~km})$ below $x=50 \mathrm{~km}$.

Fig. 5(d) highlights additional features, and makes it possible to further understand the lateral variations. Previously available body wave tomographies in the area do not have sufficient station coverage to resolve the smaller scale features of our $V s$ section, but our results are in overall agreement with the higher resolution tomography by Zhao et al. (2016a), from which we extracted the cross-section shown as background in Fig. 5(d). From west to east, we observe limited lateral variations in the external Alps (a1-a9, $\mathrm{km}-150$ to 0 ), a hitherto unknown strong low-velocity anomaly in the western internal Alps below $120 \mathrm{~km}$ depth (a10-a12, km 0-50) and high velocities beneath the Po plain (a13-a14, km 90-150). The strong low-velocity anomaly beneath the internal Western Alps is also present in the results of the $P$-wave traveltime tomographies by Zhao et al. (2016a) and Lippitsch et al. (2003), with weak amplitude in the latter. The small discrepancy of the location of the strong low-velocity anomaly between body wave and surface wave tomographies may be due to the fact that the Alps in this area has a 3-D geometry. Indeed, the surface wave models appear as located on the CIFALPS profile, while in reality they are spatial averages over arrays shifted several kilometres towards the north of the profile (see Fig. 5a).

Additional input to the analysis comes from traveltime delays of body waves. We selected two events for which $P$ and/or $S$ arrivals were clear, for which the incidence is subvertical, and which are located approximately on the great circle through $\mathrm{A}-\mathrm{A}^{\prime}$. Their locations are shown as blue stars in Fig. 2. We chose the highest quality data among those available: SKS phase (incidence $7.5^{\circ}$ to vertical, from the west), SKKS phase (incidence $6.5^{\circ}$ to vertical, from the east) and PKIKP phase (incidence $1^{\circ}$ to vertical, from the east). The traveltime differences of these phases with respect to the westernmost station CT01 are shown in Fig. 5(e). These traveltime delays are not corrected for crustal effects, but as shown in Fig. 5(e), predicted relative time delays of vertically propagating $P$ waves through the Zhao et al. (2015) crustal model are modest (note that the delays include the effect of topography). Indeed, the effect of the very deep European Moho below the Ivrea body is counterbalanced by the presence of mantle material above. The observed traveltime differences are therefore dominated by very early arrivals due to the presence of a high-velocity subduction slab beneath the eastern part of the array as known from several $P$-wave tomographies (e.g. Lippitsch et al. 2003; Piromallo \& Morelli 2003). The $S$-wave advance is surprisingly large, but clear in the seismic traces (Fig. 5e). The effect of the anomalously low velocities beneath the internal Alps (approximately $\mathrm{km} 0-50$ on the $\mathrm{A}-\mathrm{A}^{\prime}$ profile) is observed in the $S$-wave relative traveltimes as a slight positive anomaly added on top of the large negative anomaly. While the data at hand does not allow for a depth inversion, the eastwards shift of this anomaly for the event located west of the array, and westwards shift for the event located east of the array is compatible with a mantle origin of the delays.

\section{CONCLUSIONS}

This study demonstrates that array analysis, using arrays of $\sim 50 \mathrm{~km}$ aperture, is indeed possible for fundamental-mode Rayleigh waves and yields stable results across an extremely heterogeneous 3-D structure. This approach makes it possible to estimate absolute $V s$ over length scales of approximately the aperture of the array, and contains complementary information to other imaging methods, in 
particular receiver functions and $P$-wave tomography, and to regional surface wave studies. Due to the small size of the array as compared to the wavelengths under consideration, caution must be taken to avoid that spurious oscillations in the phase velocity dispersion curve has a significant influence on the inversion results. We therefore recommend first to take a conservative inversion approach of the dispersion curves, and secondly that the interpretations should be based on several arrays rather than on individual ones. Such strict considerations can probably be relaxed in less heterogeneous structures than that of the western Alps. In simpler structures, it may also be feasible to do fully joint inversions of receiver functions from individual or small groups of stations with array-based dispersion curves. In terms of array geometry, the combination in CIFALPS of a dense linear array with off-profile stations in an approximately regular grid is an efficient setup, and realistic in terms of the additional number of stations required off profile.

In terms of deep Alpine structure, we highlight three main results:

(1) The $V s(z)$ profiles are coherent with an approximately $100 \mathrm{~km}$ thick European lithosphere, in line with observations in other areas of Phanerozoic Europe unaffected by recent volcanism. Our results show dip values of the European lithosphere-asthenosphere boundary that are coherent with the Moho dip measured from controlledsource seismology and receiver function analysis (e.g. Nicolas et al. 1990; Waldhauser et al. 1998; Spada et al. 2013; Zhao et al. 2015).

(2) Absolute $V_{S}$ is high in the upper mantle beneath the Po plain, due to presence of the subducted Alpine slab, in agreement with both $V s$ models from full-waveform inversion (Zhu et al. 2012; Fichtner \& Villaseñor 2015) and $V p$ perturbation models from traveltime tomography (e.g. Lippitsch et al. 2003; Piromallo \& Morelli 2003; Zhao et al. 2016a).

(3) Our $V s(z)$ profiles confirm the results of teleseismic $P$-wave tomography (Zhao et al. 2016a) showing anomalously low velocities in the upper mantle beneath the uplifting core of the western Alps. The possible relationships between such low-velocity anomalies and uplift at the surface would require further investigation by mantle flow modelling. On the other hand, it is unlikely that such low velocities and related surface uplift are related to slab break-off, as suggested instead by Lippitsch et al. (2003).

\section{ACKNOWLEDGEMENTS}

The seismic data of the CIFALPS experiment are archived at the data centre of the Seismic Array Laboratory, Institute of Geology and Geophysics, Chinese Academy of Sciences, and are freely available at the data centre of the French Seismologic and Geodetic Network (RESIF; http://www.resif.fr/). We are most grateful to the operators of permanent broad-band seismic arrays of European countries who make their data freely available through the EIDA (European Integrated Data Archive, http://www.orfeus-eu.org/eida/eida.html). And constructive reviews from two anonymous reviewers were greatly appreciated. The CIFALPS project is funded by the State Key Laboratory of Lithospheric Evolution, China, the National Natural Science Foundation of China (grant no. 41625016) and by a grant from Labex OSUG@2020 (Investissements d'avenir ANR10 LABX56, France).

\section{REFERENCES}

Alsina, D. \& Snieder, R., 1996. Constraints on the velocity structure beneath the Tornquist-Teisseyre Zone from beam-forming analysis, Geophys. J. Int., 126, 205-218.
Alvizuri, C. \& Tanimoto, T., 2011. Azimuthal anisotropy from array analysis of Rayleigh waves in Southern California, Geophys. J. Int., 186, 11351151.

Artemieva, I.M., Thybo, H. \& Kaban, M.K., 2006. Deep Europe today: geophysical synthesis of the upper mantle structure and lithospheric processes over $3.5 \mathrm{Ga}$, Mem. Geol. Soc. Lond., 32, 11-41.

Bartzsch, S., Lebedev, S. \& Meier, T., 2011. Resolving the lithosphereasthenosphere boundary with seismic Rayleigh waves, Geophys. J. Int., 186, 1152-1164.

Baumont, D., Paul, A., Zandt, G., Beck, S.L. \& Pedersen, H., 2002. Lithospheric structure of the central Andes based on surface wave dispersion, J. geophys. Res., 107(B12), 2371, doi:10.1029/2001JB000345.

Bodin, T. \& Maupin, V., 2008. Resolution potential of surface wave phase velocity measurements at small arrays, Geophys. J. Int., 172, 698-706.

Bourova, E., Kassaras, I., Pedersen, H.A., Yanovskaya, T., Hatzfeld, D. \& Kiratzi, A., 2005. Constraints on absolute $\mathrm{S}$ velocities beneath the Aegean Sea from surface wave analysis, Geophys. J. Int., 160, 1006-1019.

Bruneton, M. et al., 2004. Layered lithospheric mantle in the central Baltic Shield from surface waves and xenolith analysis, Earth planet. Sci. Lett., 226, 41-52.

Chopin, C., 1984. Coesite and pure pyrope in high-grade blueschists of the Western Alps: a first record and some consequences, Contrib. Mineral. Petrol., 86, 107-118.

Cotte, N., Pedersen, H. \& Group, T.W., 2002. Sharp contrast in lithospheric structure across the Sorgenfrei-Tornquist Zone as inferred by Rayleigh wave analysis of TOR1 project data, Tectonophysics, 360, 75-88.

De Barros, L., Pedersen, H.A., Métaxian, J.-P., Valdés-Gonzalez, C. \& Lesage, P., 2008. Crustal structure below Popocatépetl Volcano (Mexico) from analysis of Rayleigh waves, J. Volc. Geotherm. Res., 170, 5-11.

Dewey, J.F., Helman, M.L., Knott, S.D., Turco, E. \& Hutton, D.H.W., 1989. Kinematics of the western Mediterranean, Geol. Soc. Lond. Spec. Publ., 45, 265-283.

Dost, B., 1990. Upper mantle structure under western Europe from fundamental and higher mode surface waves using the NARS array, Geophys. J. Int., 100, 131-151.

Dziewonski, A.M. \& Anderson, D.L., 1981. Preliminary reference Earth model, Phys. Earth planet. Inter., 25, 297-356.

Faccenna, C. et al., 2014. Mantle dynamics in the Mediterranean, Rev. Geophys., 52, 283-332.

Fichtner, A., Trampert, J., Cupillard, P., Saygin, E., Taymaz, T., Capdeville, Y. \& Villasenor, A., 2013. Multiscale full waveform inversion, Geophys. J. Int., 194, 534-556.

Fichtner, A. \& Villaseñor, A., 2015. Crust and upper mantle of the western Mediterranean - constraints from full-waveform inversion, Earth planet. Sci. Lett., 428, 52-62.

Foster, A., Ekström, G. \& Hjörleifsdóttir, V., 2014a. Arrival-angle anomalies across the USArray Transportable Array, Earth planet. Sci. Lett., 402, 58 68.

Foster, A., Ekström, G. \& Nettles, M., 2014b. Surface wave phase velocities of the Western United States from a two-station method, Geophys. J. Int. 196(2), 1189-1206.

Fox, M., Herman, F., Kissling, E. \& Willett, S.D., 2015. Rapid exhumation in the Western Alps driven by slab detachment and glacial erosion, Geology, 43, 379-382.

Friederich, W., 1998. Wave-theoretical inversion of teleseismic surface waves in a regional network: phase-velocity maps and a three-dimensional upper-mantle shear-wave-velocity model for southern Germany, Geophys. J. Int., 132, 203-225.

Geissler, W.H., Sodoudi, F. \& Kind, R., 2010. Thickness of the central and eastern European lithosphere as seen by $\mathrm{S}$ receiver functions, Geophys. $J$. Int., 181, 604-634.

Goffé, B., Bousquet, R., Henry, P. \& Le Pichon, X., 2003. Effect of the chemical composition of the crust on the metamorphic evolution of orogenic wedges, J. Metamorph. Geol., 21, 123-141.

Guillot, S., Hattori, K., Agard, P., Schwartz, S. \& Vidal, O., 2009. Exhumation processes in oceanic and continental subduction contexts: a review, in Subduction Zone Geodynamics, eds Lallemand, S. \& Funiciello, F., pp. 175-205, Springer, Berlin, Heidelberg. 
Handy, M.R., Schmid, S.M., Bousquet, R., Kissling, E. \& Bernoulli, D., 2010. Reconciling plate-tectonic reconstructions of Alpine Tethys with the geological-geophysical record of spreading and subduction in the Alps, Earth-Sci. Rev., 102, 121-158.

Herrmann, R.B., 2013. Computer programs in seismology: an evolving tool for instruction and research, Seismol. Res. Lett., 84, 1081-1088.

INGV Seismological Data Centre, 1997. Rete Sismica Nazionale (RSN), Istituto Nazionale di Geofisica e Vulcanologia (INGV), Italy, doi:10.13127/SD/X0FXnH7QfY.

Ikeda, T. \& Tsuji, T., 2014. Azimuthal anisotropy of Rayleigh waves in the crust in southern Tohoku area, Japan, J. geophys. Res., 119, 8964-8975.

Jolivet, L. \& Faccenna, C., 2000. Mediterranean extension and the AfricaEurasia collision, Tectonics, 19, 1095-1106.

Kaviani, A., Paul, A., Bourova, E., Hatzfeld, D., Pedersen, H. \& Mokhtari, M., 2007. A strong seismic velocity contrast in the shallow mantle across the Zagros collision zone (Iran), Geophys. J. Int., 171, 399-410.

Kennett, B., Engdahl, E. \& Buland, R., 1995. Constraints on seismic velocities in the Earth from traveltimes, Geophys. J. Int., 122, 108-124.

Kissling, E., 1993. Deep structure of the Alps - what do we really know?, Phys. Earth planet. Inter, 79, 87-112.

Legendre, C.P., Meier, T., Lebedev, S., Friederich, W. \& Viereck-Götte, L., 2012. A shear wave velocity model of the European upper mantle from automated inversion of seismic shear and surface waveforms, Geophys. J. Int., 191, 282-304.

Levshin, A., Yanovskaya, T., Lander, A., Bukchin, B., Barmin, M., Ratnikova, L. \& Its, E., 1989. Seismic surface waves in a laterally inhomogeneous Earth, Mod. Approach. Geophys., 9, 131-169.

Lippitsch, R., Kissling, E. \& Ansorge, J., 2003. Upper mantle structure beneath the Alpine orogen from high-resolution teleseismic tomography, J. geophys. Res., 108(B8), 2376, doi:10.1029/2002JB002016.

Lombardi, D., Braunmiller, J., Kissling, E. \& Giardini, D., 2008. Moho depth and Poisson's ratio in the Western-Central Alps from receiver functions, Geophys. J. Int., 173, 249-264.

Malusà, M.G. et al., 2015. Contrasting styles of (U)HP rock exhumation along the Cenozoic Adria-Europe plate boundary (Western Alps, Calabria, Corsica), Geochem. Geophys. Geosyst., 16, 1786-1824.

Maupin, V., 2011. Upper-mantle structure in southern Norway from beamforming of Rayleigh wave data presenting multipathing, Geophys. J. Int., $\mathbf{1 8 5}, 985-1002$.

Mechie, J. et al., 2012. Crustal and uppermost mantle velocity structure along a profile across the Pamir and southern Tien Shan as derived from project TIPAGE wide-angle seismic data, Geophys. J. Int., 188, 385-407.

Meier, T., Soomro, R.A., Viereck, L., Lebedev, S., Behrmann, J.H., Weidle, C., Cristiano, L. \& Hanemann, R., 2016. Mesozoic and Cenozoic evolution of the Central European lithosphere, Tectonophysics, 692, 58-73.

Molinari, I., Argnani, A., Morelli, A. \& Basini, P., 2015. Development and testing of a 3D seismic velocity model of the Po Plain sedimentary basin, Italy, Bull. seism. Soc. Am., 105, 753-764.

Nicolas, A., Hirn, A., Nicolich, R. \& Polino, R., 1990. Lithospheric wedging in the western Alps inferred from the ECORS-CROP traverse, Geology, 18, 587-590.

Nocquet, J.-M. et al., 2016. Present-day uplift of the western Alps, Sci. Rep., 6, 28404, doi:10.1038/srep28404.

Pedersen, H.A., Boué, P., Poli, P. \& Colombi, A., 2015. Arrival angle anomalies of Rayleigh waves observed at a broadband array: a systematic study based on earthquake data, full waveform simulations and noise correlations, Geophys. J. Int., 203, 1626-1641.

Pedersen, H.A., Coutant, O., Deschamps, A., Soulage, M. \& Cotte, N., 2003. Measuring surface wave phase velocities beneath small broad-band arrays: tests of an improved algorithm and application to the French Alps, Geophys. J. Int., 154, 903-912.

Pedersen, H.A., Debayle, E. \& Maupin, V., 2013. Strong lateral variations of lithospheric mantle beneath cratons - example from the Baltic Shield, Earth planet. Sci. Lett., 383, 164-172.

Piromallo, C. \& Morelli, A., 2003. P wave tomography of the mantle under the Alpine-Mediterranean area, J. geophys. Res., 108(B2), 2065, doi:10.1029/2002JB001757.
Pollitz, F.F., 1999. Regional velocity structure in northern California from inversion of scattered seismic surface waves, J. geophys. Res., 104, $15043-$ 15072.

RESIF, 1995. RESIF-RLBP French Broad-band network, RESIF-RAP strong motion network and other seismic stations in metropolitan France, RESIF-Réseau sismologique \& géodésique français, doi:10.15778/RESIF.FR.

Salaün, G. et al., 2012. High-resolution surface wave tomography beneath the Aegean-Anatolia region: constraints on upper-mantle structure, Geophys. J. Int., 190, 406-420.

Shapiro, N.M. \& Ritzwoller, M.H., 2002. Monte-Carlo inversion for a global shear-velocity model of the crust and upper mantle, Geophys. J. Int., 151, $88-105$.

Spada, M., Bianchi, I., Kissling, E., Agostinetti, N.P. \& Wiemer, S., 2013. Combining controlled-source seismology and receiver function information to derive 3-D Moho topography for Italy, Geophys. J. Int., 194, $1050-1068$.

Spakman, W., van der Lee, S. \& van der Hilst, R., 1993. Travel-time tomography of the European-Mediterranean mantle down to $1400 \mathrm{~km}$, Phys. Earth planet. Inter., 79, 3-74.

Stehly, L., Fry, B., Campillo, M., Shapiro, N., Guilbert, J., Boschi, L. \& Giardini, D., 2009. Tomography of the Alpine region from observations of seismic ambient noise, Geophys. J. Int., 178, 338-350.

Tang, Q. \& Chen, L., 2008. Structure of the crust and uppermost mantle of the Yanshan Belt and adjacent regions at the northeastern boundary of the North China Craton from Rayleigh Wave Dispersion Analysis, Tectonophysics, 455, 43-52.

Tanimoto, T. \& Prindle, K., 2007. Surface wave analysis with beamforming, Earth Planets Space, 59, 453-458.

University of Genova, 1967. Regional Seismic Network of North Western Italy, International Federation of Digital Seismograph Networks, Other/Seismic Network, doi:10.7914/SN/GU.

Waldhauser, F., Kissling, E. \& Ansorge, J., 1998. Three dimensional interface modelling with two-dimensional seismic data: the Alpine crustmantle boundary, Geophys. J. Int., 135, 264-278.

Weidle, C. \& Maupin, V., 2008. An upper-mantle S-wave velocity model for Northern Europe from Love and Rayleigh group velocities, Geophys. J. Int., 175, 1154-1168.

Wielandt, E., 1993. Propagation and structural interpretation of non-plane waves, Geophys. J. Int., 113, 45-53.

Zhao, L. et al., 2015. First seismic evidence for continental subduction beneath the Western Alps, Geology, 43, 815-818.

Zhao, L. et al., 2016a. Continuity of the Alpine slab unraveled by highresolution P wave tomography, J. geophys. Res., 121, 8720-8737.

Zhao, L., Paul, A., Solarino, S. \& RESIF, 2016b. Seismic network YP: CIFALPS temporary experiment (China-Italy-France Alps seismic transect); RESIF-Réseau Sismologique et géodésique Français. Available at: https://doi.org/10.15778/RESIF.YP2012.

Zhu, H., Bozdag, E., Peter, D. \& Tromp, J., 2012. Structure of the European upper mantle revealed by adjoint tomography, Nat. Geosci., 5, 493-498.

Zhu, H., Bozda ğ, E. \& Tromp, J., 2015. Seismic structure of the European upper mantle based on adjoint tomography, Geophys. J. Int., 201, 18-52.

\section{SUPPORTING INFORMATION}

Supplementary data are available at $G J I$ online.

Figure S1. Vertical component records after the pre-processing of CIFALPS stations (CT01-CT46) along the profile AA' for the 2013 June 24 , earthquake arriving approximately along the great circle that goes through the profile.

Figure S2. Mean absolute deviation (difference between observed arrival direction and the theoretical one as predicted for the centre of the array) as a function of period. For each period, the colour of data points corresponds to the number of events contributing to the average. To stabilize the measurement, the arrival angle $\theta_{\mathrm{k}}(f)$ here 
is calculated by using all the stations in neighbouring arrays A1 and A2 which are located on similar crustal structures.

Figure S3. Azimuth deviations across the CIFALPS profile for three events, as observed using the 14 small arrays. The deviations are calculated as the difference between the observed arrival direction and the direction of the great circle as predicted for the centre of mass of the array.

Figure S4. Average $V s(z)$. Red solid line: shear velocity $V_{s}(z)$ calculated as the average model for arrays a1-a14. This $V_{S}(z)$ serves as reference profile for Fig. 5(b). Green solid line: shear velocity
$\operatorname{Vs}(z)$ calculated as the average model forarrays A2, A3, A4 and A7, which cover the approximately same geographical area as arrays a1-a14.

Table S1. Configuration of the arrays A1-A7 and a1-a14.

Please note: Oxford University Press is not responsible for the content or functionality of any supporting materials supplied by the authors. Any queries (other than missing material) should be directed to the corresponding author for the paper. 